\title{
PERTANIAN CERDAS SEBAGAI UPAYA INDONESIA MANDIRI PANGAN
}

\author{
Oleh : \\ Hanisa Sismaya Lestari \\ Dosen Fakultas Sains Terapan UNSUR
}

\begin{abstract}
Abstrak
Saat ini teknologi di dunia semakin berkembang begitu cepat, termasuk di Indonesia. Teknologi mulai masuk ke semua sektor, tak terkecuali sektor pertanian. Era Indrusti 4.0 mendorong sumber daya manusia menggunakan teknologi informasi dalam semua kegiatan agar lebih efektif dan efisien. Sumber daya manusia tersebut termasuk para petani Indonesia. Para petani ini harus dibekali wawasan serta pengalaman mengenai teknologi informasi khususnya penggunaan teknologi di sektor pertanian. Dengan hal ini diharapkan dapat meningkatkan kompetensi para petani dalam memperbaiki kualitas dan kuantitas pertanian. Adapun salah satu inovasi pertanian adalah pertanian cerdas. Pertanian cerdas merupakan suatu teknologi yang di dalamya mengintegrasikan kebutuhan data para petani seperti informasi cuaca, pemilihan bibit, penanggulangan hama, dan budidaya. Indonesia mandiri pangan adalah Indonesia sebagai negara mampu memenuhi kebutuhan pangan secara nasional, tanpa harus menerima pasokan pangan dari negara lain. Indonesia adalah negara yang kaya akan sumber daya alam dan memiliki seluruh prasyarat untuk mewujudkan kemandirian tersebut. Metode yang digunakan dalam makalah ini adalah hasil kajian pustaka ilmiah.
\end{abstract}

Kata Kunci : Pertanian Cerdas, Indonesia Mandiri Pangan.

\begin{abstract}
At this point the technology evolving so quickly in the world, including in Indonesia. The technology is starting to go into all sectors, the agricultural sector was no exception. The era of Indrusti 4.0 push buman resources using information technology in all activities in order to more effectively and efficiently. The human resources including the farmers Indonesia. The farmers must be provided insights and experiences about information technology, especially the use of technology in the agricultural sector. With this expected to increase the competence of farmers in improving the quality and quantity of farming. As for the agricultural innovation is one of the smart farming. Smart farming is a technology that integrates the data needs of the farmers such as weather information, the selection of seeds, pest prevention, and cultivation. Independent Indonesia food is Indonesia as the country is able to fulfill the needs of food nationally, without having to receive the food supply from other countries. Indonesia is country rich in natural resources and have the whole prerequisites to realize self-reliance. The methods used in this paper is the result of scientific literature review.
\end{abstract}

Keyword: Smart Farming, Independent Indonesia Food. 


\section{PENDAHULUAN}

Manusia untuk bertahan hidup membutuhkan makanan sebagai sumber energi dalam tubuh untuk melakukan berbagai aktivitas. Adapun makanan yang dikonsumsi manusia disebut pangan. Berdasarkan Undang -Undang No 18 Tahun 2012 pada pasal 1 ayat 1 menyatakan pangan adalah segala sesuatu yang berasal dari sumber hayati produk pertanian, perkebunan, kehutanan, perikanan, pertenakan, perairan dan air baik yang diolah maupun yag tidak diolah yang diperuntukkan sebagai makanan atau minuman bagi konsumsi manusia, termasuk bahan tambahan pangan, bahan baku pangan dan bahan launnya yang digunakan dalam proses penyiapan, pengolahan dan/ atau pembuatan makanan dan minuman.

Dalam kehidupan sehari-hai, manusia tidak terlepas dari yang namanya pangan. Kemudian dalam memenuhi secara kuantitas, perlu adanya kemandirian pangan. Adapun maksud dari kemandirian pangan menurut UndangUndang No. 18 Tahun 2012 pada Pasal 1 ayat 3, adalah kemampuan negara dan bangsa dalam memproduksi pangan yang beraneka ragam dari dalam negeri yang dapat menjamin pemenuhan kebutuhan [angan yang cukup sampai ditingkat perseorangan dengan memanfaatkan potensi sumber daya alam, manusia sosial, ekonomi dan kearifan lokal secara martabat.

Dalam proses pemenuhan kebutuhan pangan yang memerlukan kuatitas yang banyak, sehingga ada kalanya membutuhkan impor pangan dari luar negara Indonesia . Menurut UndangUndang No 18 Tahun 2012 pada Pasal 1 ayat 25 menyatakan bahwa impor pangan kegiatan memasukkan pangan ke dalam daerah pabean negara Republik Indonesia yang meliputi wiyalah darat, perairan, dan ruang udara di atasnya, tempat-tempat tertentu di Zona Ekonomi Eklusif dan landas kontinen.

Berdasarkan pengertian di atas bahwa Indonesia Mandiri Pangan akan tercapai ketika Indonesia mampu memproduksi pangan untuk pemenuhan kebutuhan pangan secara nasional tanpa bantuan impor pangan dari negara lain.

Pertanian cerdas adalah sebuah sistem pertanian mutkahir yang didukung dengan teknologi masa kini untuk menunjang produktivitas hasil pertanian agar lebih maksimal, sistem ini bertujuan untuk mengatur dan memprediksi hasil panen serta masalah yang dihadapi oleh para petani (S. Trilles, A. Calia, Ó. Belmonte, J. Torres-Sospedra, R. Montoliu, and J. Huerta, 2017) dalam (Taufik Hidayat, 2017).

Pertanian cerdas telah dikembangkan menggunakan perangkat sensor dan internet of things untuk mematikan dan menyalakan alat penyiram, mengukur kelembapan dan unsur hara tanah, memantau kondisi air dan cuaca, sampai mengukur volume hasil panen ketika penuaian (R. Van Hooijdonk 2015), (M. Ryu, J. Yun, T. Miao, I. Y. Ahn, S. C. Choi, and J. Kim,2015), (A. McBratney, B. Whelan, T. Ancev, and J. Bouma, 2005) dalam (Ventje J. L. Engel, Sinung Suakanto, 2016). Dengan menggunakan sistem internet of things ini diharapkan bisa membantu para petani untuk menghasilkan panen yang diharapkan. Karena penerapan internet of things ini sangat bisa diandalkan karena sensor yang digunakan dapat diandalkan keakuratan datanya sehingga para petani dapat mengontrol produktivitas hasil panen ( $\mathrm{S}$. Trilles, A. Calia, Ó. Belmonte, J. TorresSospedra, R. Montoliu, and J. Huerta, 2017) dalam (Taufik Hidayat, 2017).

Pembahasan mengenai pertanian cerdas selalu menjadi bahan yang menarik untuk dikaji, karena teknologi semakin berkembang, dan semakin besar kebutuhan pangan maka dengan meamanfaatkan teknologi dibutuhkan cara untuk mengelola pertanian secara cerdas. Maksud dari pertanian secara cerdas adalah adalah dengan cara memanfaatkan teknologi informasi dan komunikasi untuk membuat sebuah sistem pertanian dengan alur pengawasan sampai pengendalian secara cerdas yang berjalan secara otomatis. Selain Selain 
cerdas, hal ini dapat dipantau secara jara jauh selama terknoneksi internet.

Berdasarkana pemaparan, di atas tujuan studi literatur ini untuk mengetahui bagaiaman mewujudkan Indonesia mandiri pangan dengan menggunakan pertanian cerdas.

\section{METODE PENELITIAN}

Metode yang digunakan dalam tulisan ini, merupakan metode dekriptif. Metode yang digunakan dalam makalah ini adalah hasil kajian pustaka ilmiah dengan cara mengkaji Undang-Undang dan jurnal-jurnal ilmiah sebagai referensi.

\section{HASIL DAN PEMBAHASAN}

Menurut Ventje J. L. Engel, Sinung Suakanto (2016) berikut adalah arsitektur sistem pertanian cerdas menggunakan internet of things sebagai berikut. Adapun pada sistem ini memiliki enam modul konsep terdiri dari tahapan pengawasa, pengelolaan, perencanaan, distribusi informasi, sistem pendukung keputusan dan kendali. Adapun arsitektur sistem ini dengan cara membagi lahan pertanian menjadi petak. Satu petak berukuran $2 \times 2$ meter dan untuk node ssensor akan ditempatkan pada petak tersebut. Arsitektur sistem tersebut apabila digambarkan sebagai berikut. Ventje J. L. Engel, Sinung Suakanto (2016)

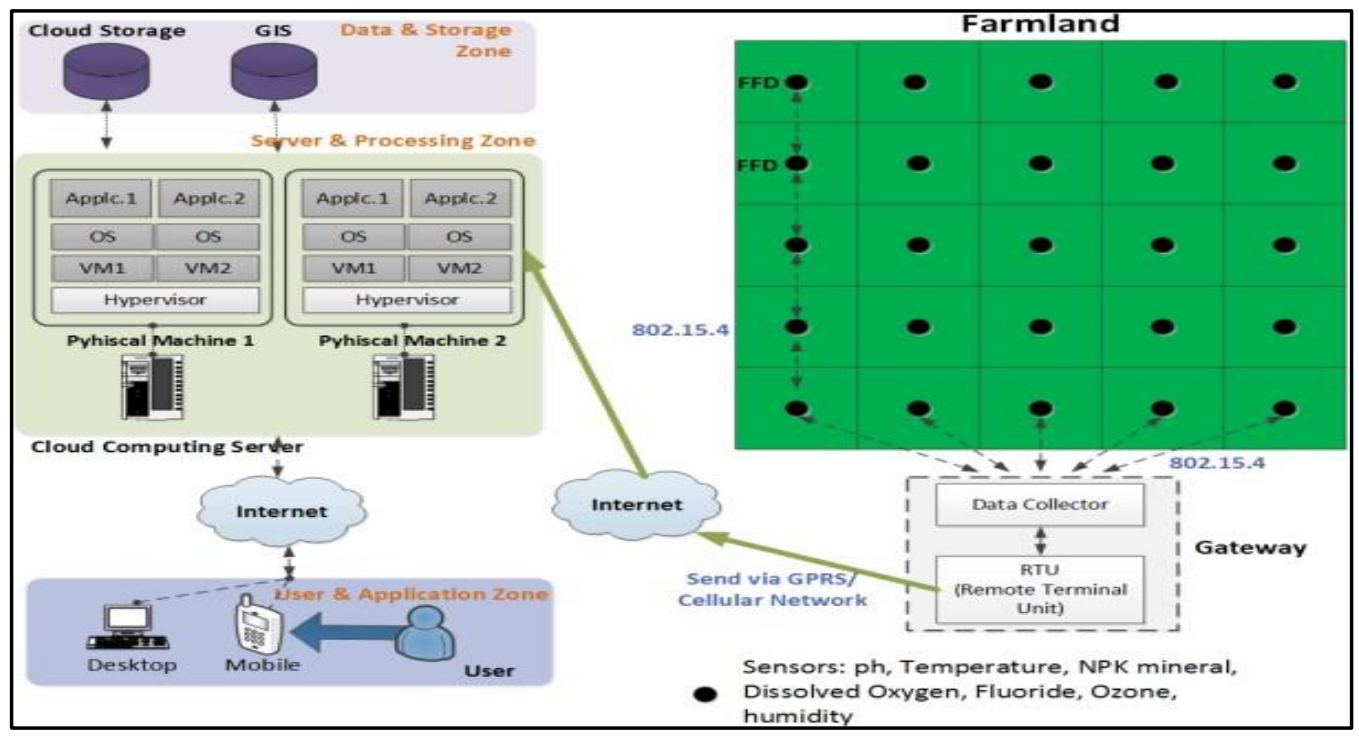

Gambar 1. Arsitektur Pertanian Cerdas.

Berdasarkan gambar di atas terlihat bahwa antara lahan pertanian dan teknologi terdapat konetivitas sehingga para petani akan mudah melihat sejauh mana perkembangan panen. Apabila pertanian di Indonesia menggunakan sistem pertanian cerdas di masa depan tentu dapat lebih maksimal dalam hal manajemen pertanian. Tentunya para petani harus dibekali kompetensi menggunakan teknologi pada, infrastruktur juga harus menunjang sistem pertanian cerdas ini. Diharapkan hal ini akan berdampak pada hasil panen yang akan bisa lebih dikontrol, kedepannya dengan adanya sistem ini Indonesia akan memiliki hasil pangan yang lebih banyak dan berkualitas baik sehingga Indonesia bisa Mandiri Pangan.

Saat ini dengan jumlah penduduk Indonesia yang terus meningkat. Dalam memenuhi kebutuhan pangan nasional yang juga semakin meningkat, kebutuhan pangan Indonesia masih cenderung dipenuhi dengan cara impor.

Sebenarnya dengan sumber daya alam yang mumpuni, Indonesia adalah negeri yang kaya, lahan pertanian yang luas, tanahnya subur dan sangat memungkinkan untuk dapat memenuhi kebutuhan pangan secara mandiri. Berdasarkan data Kementerian Pertanian, 
2013 dalam (Budhi Santoso, 2014) Indonesia mempunyai sumberdaya lahan yang cukup luas dengan berbagai keragaman dan karakteristik. Namun dari daratan seluas 189,1 juta ha sekitar 157,2 juta ha diantaranya merupakan lahan sub optimal (LSO), sedangkan sisanya seluas 31,9 juta ha adalah lahan subur (optimal) dengan berbagai tingkat kesuburan. Sebagian besar lahan tersebut sudah dimanfaatkan untuk lahan pertanian dan untuk berbagai penggunaan. Secara alamiah seluas 123,1 juta ha dari LSO adalah lahan kering dan 34,1 juta adalah lahan basah (rawa). Lahan kering terluas merupakan lahan kering masam atau lahan kering beriklim basah yang tersebar hampir di seluruh wilayah Indonesia, terutama di Sumatera. Kalimantan dan Papua. Lahan kering beriklim kering seluas 13,3 juta ha tersebar di Jatim, Bali, NTT, NTB, LSO basah terdiri dari 14,9 juta ha lahan gambut, seluas 11,0 juta ha berupa lahan rawa pasang surut dan 9,3 juta ha berupa lahan rawa lebak. Namun pada pelaksanananya memang ada hambatan aseperti yang dikemukakan pada gambar di bawah ini:

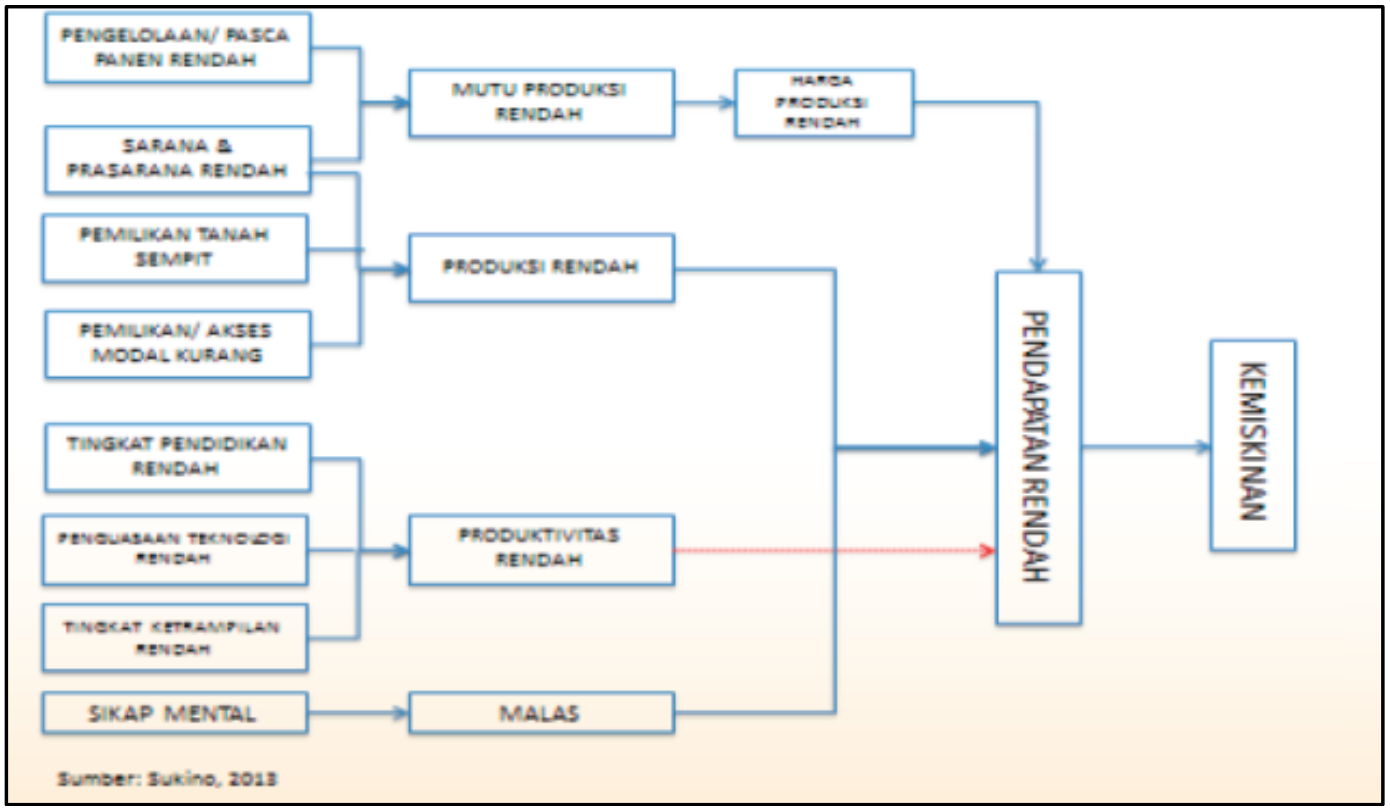

Gambar 2. Kelemahan Pertanian.

Berdasarkan gambar di atas terdapat delapan kelemahan pertanian Indonesia Sukino, 2013 dalam (Budhi Santoso, 2014) mengemukakan sebagai berikut:

1. Pengelolaan/pasca panen rendah;

2. Infrastruktur (sarana \& prasarana kurang);

3. Pemilikan lahan sempit;

4. Pemilihan/akses modal kurang;

5. Tingkat pendidikan rendah;

6. Penguasaan teknologi rendah;

7. Tingkat ketermapilan rendah;

8. Sikap mental;

Ke delapan hal ini berdampak pada hasil panen yang urang maksimal dan masih kurang. Sedangkan pertumbuhan dan kondisi penduduk
Indonesia yang semakin meningkat setiap tahunnya. Ketimpangan dua hal ini menjadikan Indonesia belum mampu menjadi Indonesia Mandiri Pangan.

Ketimpangan ini sangat krusial bagi Indonesia karena apabila tidak ditangani Indonesia akan mengalami kekurangan pangan atau krisis pangan. Diharapkan pertanian Indonesia dapat mencontoh pertanian dunia yang sebagain besar sudah menerapkan sistem ini. Teknologi jika digunakan dengan baik akan menjadi baik. Melalui pertanian cerdas diharapkan dapat hadir sebagai solusi untuk memaksimalkan hasil panen baik dari segi kualitas maupun kuantintasnya. 


\section{KESIMPULAN}

Berdasarkan hasil dan pembahasan yang telah dijelaskan pada bagian sebelumnya, maka penelitian ini menyimpulkan beberapa hal untuk mewrujudkan Indonesia Mandiri Pangan perlu adanya perubahan pola pikir bahwa Indonesia mampu menjadi swasembada pangan. Pemanfaatan lahan pertanian secara maksimal, penggunaan teknologi . Dan tentunya harus ada dukungan dari berbagai pihak seperti petani, pelaku usaha, masyarakat juga pemerintah untuk bersinergi bersama memajukan pangan Indonesia. Agar Indonesia mampu mencukupi kebutuhan pangan dan bahkan bisa mengekspor pangan ke negara lain.

\section{DAFTAR PUSTAKA}

McBratney, B. Whelan, T. Ancev, and J. Bouma. Future Directions of Precision Agriculture. 2004. Precis. Agric., Vol. 6. No. Hal, 7-23, 2005.

Budhi Santoso. 2004. Menuju Kemandirian Pangan 2015-2025. Edisi 01 Tahun XX.

M. Ryu, J. Yun, T. Miao, I. Y. Ahn, S. C. Choi, and J. Kim, "Design and implementation of a connected farm for smart farming system," in
SENSORS, 2015 IEEE, 2015, pp. $1-4$.

R. van Hooijdonk. 2015. Smart farming: the new agricultural benchmark Trendwatchter en Futurist Richard van Hooijdonk. [Online]. Available:

https://en.richardvanhooijdonk.c om/smart-farming-new-

benchmark/.

S. Trilles, A. Calia, Ó. Belmonte, J. Torres-Sospedra, R. Montoliu, and J. Huerta. 2017. Deployment of an open sensorized platform in a smart city context. Futur. Gener. Comput. Syst. Vol. 76, Hal. 221233.

Sukino. 2013. Membangun Pertanian dengan Pemberdayaan Masyarakat Tani: Terobosan Menanggulangi Kemiskinan. Pustaka Baru Press. Jogjakarta.

Taufik Hidayat. 2017. Internet of Things Smart Agriculture on Zigbee: A Systematic Review. IncomTech, Jurnal Telekomunikasi dan Komputer, Vol. 8. No.1.

Undang-Undang No 18 Tahun 2012 tentang Pangan.

Ventje J. L. Engel, Sinung Suakanto, 2016. Model Inferensi Konteks Internet of Things pada Sistem Pertanian Cerdas. Jurnal Telematikan. Vol. 11. No. 2. Intitut Teknologi Harapan Bangsa. 